\title{
Outcome of caesarean section at the Edward Francis Small Teaching Hospital, Banjul The Gambia
}

\author{
Patrick Idoko ${ }^{1,2}$, Matthew Anyanwu ${ }^{1,2}$
}

1. Edward Francis Small Teaching Hospital, Banjul The Gambia.

2. School of Medical and Allied Health Sciences, University of The Gambia.

\begin{abstract}
:
Background: Caesarean section is a very important procedure to decrease maternal and perinatal morbidity and mortality. Anecdotal evidence suggests that more than half of all caesarean sections done in The Gambia are done at the Edward Francis Small Teaching Hospital.

Objective: The aim of the study was to determine the caesarean section rate at the Edward Francis Small teaching Hospital. The study also aimed to determine the socio-demographic factors associated with caesarean section and maternal and fetal outcomes of caesarean section at the hospital.

Method: A retrospective review of all caesarean sections carried out at the Edward Francis Small Teaching Hospital from $1^{\text {st }}$ January 2014 to $31^{\text {st }}$ December 2014 was done. Data was extracted from patients' record. Descriptive statistics was done using Epi Info 7 statistical software.

Results: The Caesarean section rate in the hospital is $24.0 \%$. The commonest indications for caesarean section were previous caesarean section (20.6\%) and cephalopelvic disproportion (20.2\%). There were 21 maternal deaths (1.8\%) and 71 fresh stillbirths $(6.0 \%)$ in the study population.

Conclusion: About a quarter of all deliveries in the hospital were caesarean sections most of which were done as emergencies. The commonest indications for caesarean section were cephalopelvic disproportion and previous caesarean section.

Keywords: Caesarean section, Banjul The Gambia.

DOI: https://dx.doi.org/10.4314/ahs.v18i1.20

Cite as: Idoko P, Anyanwu M. Outcome of caesarean section at the Edward Francis Small Teaching Hospital, Banjul The Gambia. Afri Health Sci 2018;18(1): 157-165. bttps://dx.doi.org/10.4314/abs.v18i1.20
\end{abstract}

\section{Introduction}

Caesarean section, a surgical procedure to deliver a baby in which an incision is made on the maternal abdomen and a second one on her uterus is an important tool for reducing maternal and perinatal morbidity and mortality. The exact origin of the procedure is shrouded in mystery and controversy. Before the later half of the $19^{\text {th }}$ century, the procedure was associated with almost certain
Corresponding author:
Patrick Idoko,
Edward Francis Small
Teaching Hospital, Banjul The Gambia.
Email: patidoko@gmail.com

maternal mortality ${ }^{1}$. However, with the advent of safe anaesthetic techniques, aseptic procedure and antibiotics, caesarean section has become a veritable tool in the armamentarium of physicians. In the past 30 years, the World Health Organisation (WHO) has evolved from recommending an ideal caesarean section rate of 10-15\% to recommending that caesarean section be provided to all women in need rather than striving to achieve a specific rate re $^{2,3}$. Caesarean section rates higher than $10 \%$ are not associated with reductions in maternal and newborn mortality rate ${ }^{3}$.This change was due to emerging evidence of the benefits and risks of caesarean section along with significant improvements in clinical obstetric care ${ }^{4}$. Over the years, as the procedure has become safer, the indications for the surgery have also changed. Historically, 
maternal health was the most important consideration in performing a caesarean section. More recently, the indication for caesarean section has expanded to include foetal conditions and maternal request $t^{1,5,6}$. About half of the caesarean sections performed in the United States are thought to be medically unnecessary ${ }^{7}$.

The medical consequences of a rising caesarean section rate remain uncertain in the short and long term and the implications in developing countries may be more significant as the facilities and/or capacity to properly conduct safe surgery and treat surgical complications may be limited $^{8,9}$. A previous WHO study found that the rate of caesarean delivery was positively associated with adverse outcomes such as postpartum infection, postpartum antibiotic treatment and severe maternal morbidity and mortality, even after adjustment for risk factors ${ }^{10}$.

Even though caesarean section is much safer than it used to be in the past, this should not be taken to mean that the procedure is not fraught with many complications. The risk of maternal death is higher for caesarean section compared to vaginal deliveries, ${ }^{7,11}$. It is also associated with higher morbidities including infection, haemorrhage and damage to surrounding organs ${ }^{12-14}$. Other problems include prolonged hospital stay, delayed mother-child bonding and higher hospital cost ${ }^{7}$. Respiratory distress syndrome is also more common in new born delivered by elective caesarean section before 38 completed weeks of gestation ${ }^{11}$. Subsequent pregnancies following a caesarean section are also associated with increased risks including unexplained stillbirths ${ }^{15,16}$.

As the only tertiary hospital in the country, the Edward Francis Small Teaching Hospital (EFSTH) receives referral from all over The Gambia. It also serves as the apex teaching hospital in the country and is involved in the training of doctors. Maternity care in The Gambia is ab- solutely free and provided for by the government. The aim of this study was to determine the caesarean section rate at the hospital as well as to determine the socio-demographic factors associated with caesarean section. The study will also determine the outcome of caesarean section at the EFSTH. Anecdotal evidence suggests that about half of all caesarean sections performed in the country are carried out at EFSTH. This study aims to determine the caesarean section rate at EFSTH, identify the socio-demographic factors associated with caesarean section and determine the maternal and foetal outcome of caesarean sections at EFSTH.

\section{Methodology}

A descriptive cross sectional survey of all caesarean sections performed at EFSTH from $1^{\text {st }}$ January to $31^{\text {st }}$ December 2014 was done. The labour ward register and operating room register were used to identify all caesarean sections done during the study period. Data was extracted from patient's record on socio-demographic characteristics, indication for the surgery, maternal and perinatal outcomes and complications. Descriptive statistics with Epi Info 7 statistical software was used to analyze the data. Chi-square at significant level of 0.05 and confidence level of $95 \%$ was used to determine significance. Ethical approval was obtained from the ethics board of the Edward Francis Small Teaching Hospital, Banjul.

\section{Results}

Of the 4900 deliveries, 1177 were caesarean sections giving a caesarean section rate of $24.0 \%$. Table 1 shows the descriptive characteristics of parturients who had caesarean section compared with parturient who did not have caesarean section. The caesarean section rate for women with one previous caesarean section was $46.5 \%$. Women with one previous caesarean section had a 2.75 - fold increased risk of a repeat caesarean section $(p<0.0001)$. 
Table 1: Socio demographic characteristics of study population

\begin{tabular}{|c|c|c|c|}
\hline & $\begin{array}{l}\text { Caesarean } \\
\text { Section } \\
\mathrm{n}=1177(\%)\end{array}$ & $\begin{array}{l}\text { Vaginal } \\
\text { delivery } \\
\mathrm{n}=3723(\%)\end{array}$ & $\begin{array}{l}\text { RR (95\% confidence } \\
\text { interval) }\end{array}$ \\
\hline $\begin{array}{l}\text { Mean age years } \\
\text { (sd) }\end{array}$ & $29.02(7.02)$ & $28.4(6.7)$ & $\begin{array}{l}-0.62^{*}(-1.06--0.18) \\
p=0.0063\end{array}$ \\
\hline \multicolumn{4}{|l|}{ Marital Status } \\
\hline $\begin{array}{l}\text { Married } \\
\text { Single } \\
\text { Missing }\end{array}$ & $\begin{array}{l}1007(85.6) \\
17(1.4) \\
153(13.0)\end{array}$ & $\begin{array}{l}3488(93.7) \\
23(0.6) \\
212(5.7)\end{array}$ & $\begin{array}{l}0.91(0.89-0.93) \\
p=0.0025\end{array}$ \\
\hline \multicolumn{4}{|l|}{ Educational level } \\
\hline $\begin{array}{l}\text { Primary or none } \\
\text { Secondary and } \\
\text { above } \\
\text { Missing }\end{array}$ & $\begin{array}{l}776(65.9) \\
184(15.6) \\
\\
217(18.5)\end{array}$ & $\begin{array}{l}1877(50.4) \\
737(19.8) \\
1109(29.8)\end{array}$ & $\begin{array}{l}1.30(1.24-1.38) \\
p<0.0001\end{array}$ \\
\hline \multicolumn{4}{|l|}{ Parity } \\
\hline $\begin{array}{l}0 \\
1-4 \\
>4\end{array}$ & $\begin{array}{l}436(37.0) \\
590(50.1) \\
151(12.9)\end{array}$ & $\begin{array}{l}894(24.0) \\
1888(50.7) \\
941(25.3)\end{array}$ & $\begin{array}{l}0.16(0.12-0.21) \\
p<0.0001\end{array}$ \\
\hline \multicolumn{4}{|l|}{ Booking status } \\
\hline $\begin{array}{l}\text { Booked } \\
\text { Unbooked } \\
\text { Misssing }\end{array}$ & $\begin{array}{l}1017(86.4) \\
18(1.5) \\
142(12.1)\end{array}$ & $\begin{array}{l}3488(93.7) \\
24(0.6) \\
211(5.7)\end{array}$ & $\begin{array}{l}0.53(0.37-0.75) \\
p=0.0018\end{array}$ \\
\hline \multicolumn{4}{|l|}{ Referral status } \\
\hline $\begin{array}{l}\text { Referred } \\
\text { Not referred } \\
\text { Missing }\end{array}$ & $\begin{array}{l}823(69.9) \\
142(12.1) \\
212(18)\end{array}$ & $\begin{array}{l}3350(89.9) \\
194(5.2) \\
179(4.9)\end{array}$ & $\begin{array}{l}0.78(0.75-0.80) \\
p<0.0001\end{array}$ \\
\hline \multicolumn{4}{|c|}{ One previous Caesarean section } \\
\hline $\begin{array}{l}\text { Yes } \\
\text { No }\end{array}$ & $\begin{array}{l}194(16.5) \\
983(83.5)\end{array}$ & $\begin{array}{l}223(6.0) \\
3500(94.0)\end{array}$ & $\begin{array}{l}2.75(2.30-3.30) \\
p<0.0001\end{array}$ \\
\hline $\begin{array}{l}\text { Mean Blood Loss in } \\
\text { ml (sd) }\end{array}$ & $410.5(245.3)$ & $217.9(204.6)$ & $\begin{array}{l}-192.6^{*}(-206.7--178.50) \\
p<0.0001\end{array}$ \\
\hline
\end{tabular}

* difference in mean change

In table 2, the commonest indications for caesarean sec- tion were cephalo-pelvic disproportion and previous caesarean section. 
Table 2: Indication for caesarean section

\begin{tabular}{lcc}
\hline Indication for caesarean section & Frequency & Percentage \\
\hline Previous Caesarean Section & 242 & 20.6 \\
Breech Presentation & 184 & 15.6 \\
Cephalo-pelvic disproportion & 238 & 20.2 \\
Failed Induction of labour & 6 & 0.5 \\
Eclampsia & 47 & 4.0 \\
Fetal Distress & 59 & 5.0 \\
Placenta Praevia & 69 & 5.9 \\
Obstructed labour & 35 & 3.0 \\
Slow progress in labour & 67 & 5.7 \\
Abruptio Placenta & 69 & 5.9 \\
Twin pregnancy & 40 & 3.4 \\
Cord Prolapse & 20 & 1.7 \\
Retained second Twin & 20 & 1.7 \\
Failed operative delivery & 12 & 1.0 \\
Ruptured uterus & 19 & 1.6 \\
Fetal macrosomia & 12 & 1.0 \\
Pre-eclampsia & 19 & 1.6 \\
Others & 19 & 1.6 \\
\hline
\end{tabular}

Table 3 shows the common complications following surgery. The minimum blood loss documented was $100 \mathrm{ml}$ and the maximum was $985 \mathrm{ml}$ with an average of $410 \mathrm{ml}$. The mean blood loss was higher in women with caesarean section compared to women who had vaginal delivery
(Table 1) although the maximum blood loss recorded for spontaneous vaginal delivery was much higher at $2500 \mathrm{ml}$. However, $45.2 \%$ of the patients had blood transfusion about half of whom received more than 1 litre of blood. There were 21 maternal deaths $(1.8 \%)$ in the women who had caesarean section (table 3$)$.

Table 3: Complications following surgery

\begin{tabular}{lcc}
\hline Complications & Frequency & Percent \\
\hline Blood transfusion & 532 & 45.2 \\
Wound infection & 51 & 4.3 \\
Maternal death & 21 & 1.8 \\
Emergency Hysterectomy & 27 & 2.3 \\
\hline
\end{tabular}

*Hysterectomy was done for PPH in 25 cases and for severe endometritis in 2 cases

In figure 1,87\% of all caesarean sections done at the EFSTH were done as emergencies and figure 2 shows that while $6 \%$ of the caesarean section resulted in fresh stillbirth babies, macerated stillbirths were noticed in $2 \%$ of caesarean deliveries.
Table 4 shows the duration of hospitalization after surgery. The duration of stay after Caesarean section ranged from 1 day to 32 days with a mean of 4.5 days (standard deviation 3.6). 


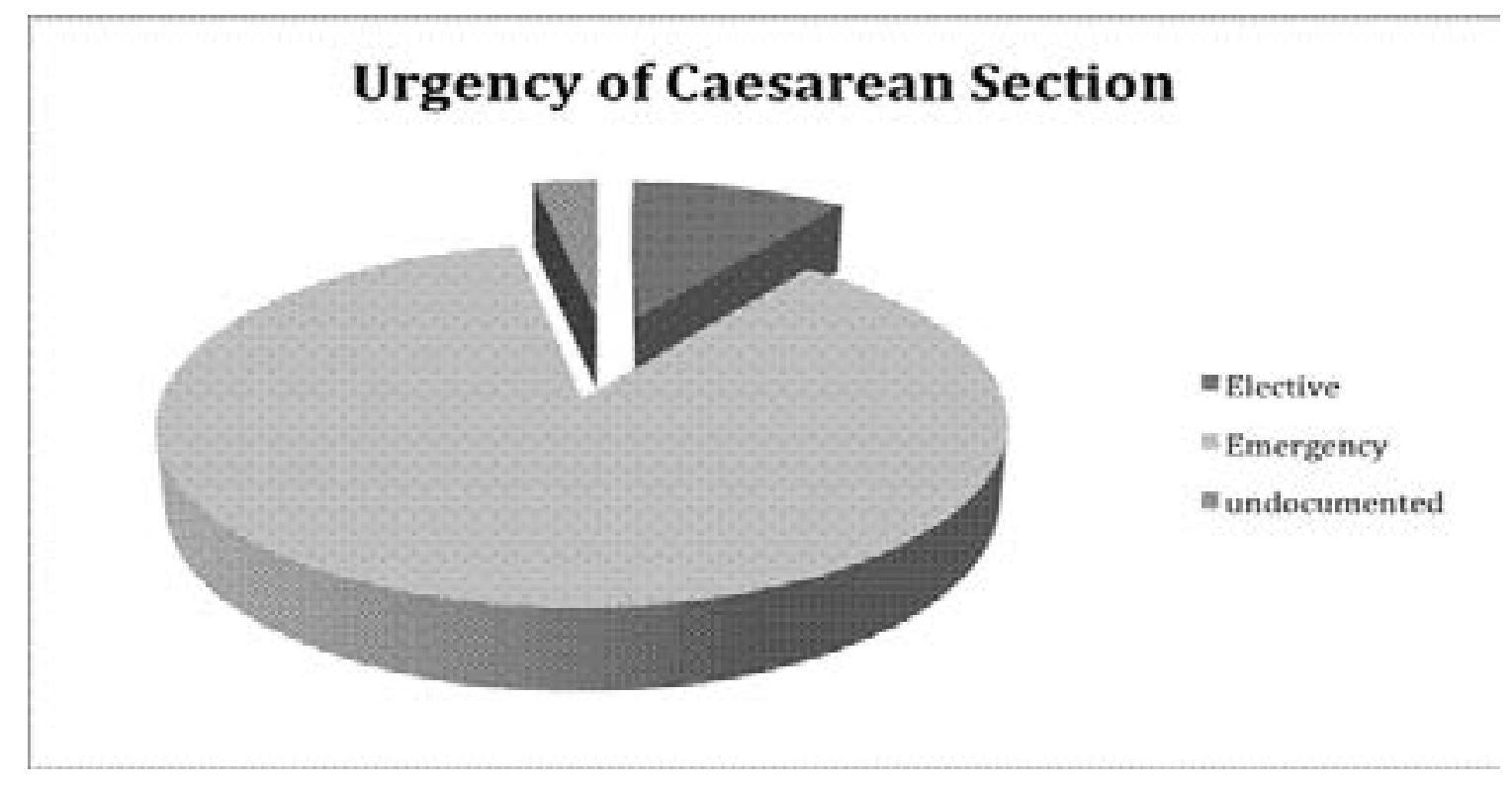

Figure 1: Urgency of Caesarean Section

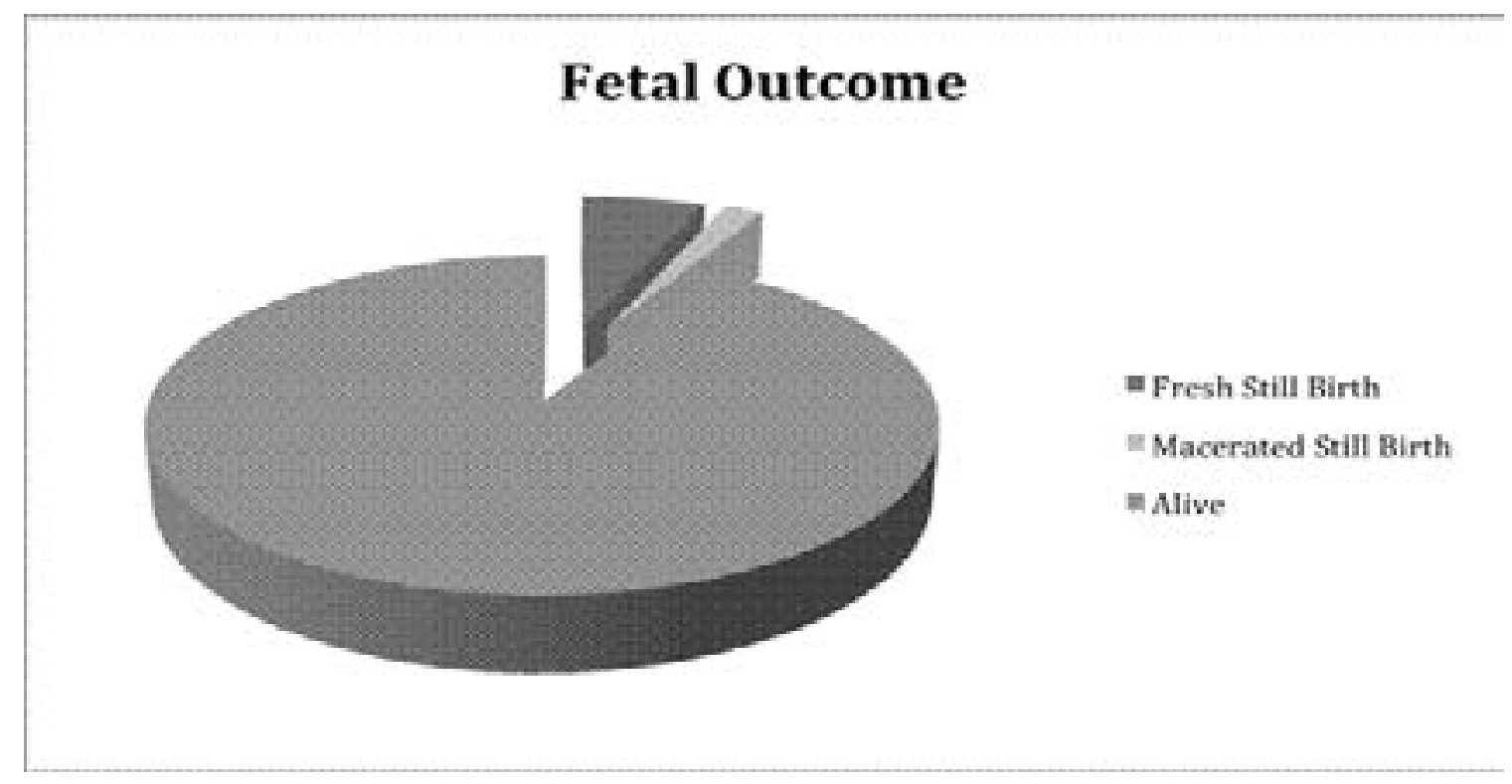

Figure 2: Foetal outcome following Caesarean Section

Table 4: Duration of hospitalization after caesarean section

\begin{tabular}{lcc}
\hline Number of days & Frequency & Percent \\
\hline $1-3$ & 617 & 53.4 \\
$4-7$ & 437 & 37.1 \\
$8-14$ & 78 & 6.6 \\
$\geq 15$ & 33 & 2.9 \\
\hline
\end{tabular}




\section{Discussion}

The rate of caesarean section in this study was $24 \%$ that is a 1.5 -fold increase from $14 \%$ in 2006 in the same hospital $^{17}$. This invariably was beyond the estimated $10-15 \%$ rate suggested by the WHO as a recommended ideal rate ${ }^{2}$. While most Scandinavian countries have maintained this rate over the years ${ }^{18}$, there has been an overall increase in rates of caesarean delivery in many parts of the world ${ }^{19}$. In the United States, China and parts of South America caesarean section rates of $33-50 \%$ are common ${ }^{20-22}$. Similarly, evidence suggests that cesarean birth rates are high and increasing in some developing countries. A study conducted at a tertiary hospital in Nigeria suggests a caesarean section rate of $27.6 \%$ which was almost 3 -fold more than the $10.4 \%$ recorded in this centre over two decades $\mathrm{ago}^{23}$. In a large population based survey conducted in 26 countries in Southern Asia or sub-Saharan Africa. The result shows wide regional variation of cesarean birth rates ranging from 3-26\%

Studies have shown that the increased rate of caesarean delivery was driven by fear of litigation, caesarean section on maternal request and previous caesarean section ${ }^{25}$.

The mean age of women who had caesarean section was slightly higher than those who did not have caesarean section but this was not statistically significant $(p=0.0063)$. Previous studies have shown that advancing maternal age increases the risk for caesarean section ${ }^{26-28}$. This was not seen in this study, as most of the parturient were highrisk patients referred from other health centres. Being married reduced the risk of having a caesarean section in our study (RR 0.91, $\mathrm{p}=0.0025$ ). This is most likely due to the fact that married women are more likely to book for antenatal care where risk assessment would have been done and managed appropriately which may reduce the need for a caesarean section.

People with no formal education or just primary school level education were 1.30 times more likely to have a caesarean section than their more educated counterparts as shown in Table $1(\mathrm{p}<0.0001)$. While some previous studies have shown that women with higher education or higher socioeconomic status were more likely to have a caesarean section ${ }^{29-31}$, other studies have shown the opposite $^{32,33}$. The EFSTH is a public health facility that offers free comprehensive maternity care. Thus, majority of the patients are from the lower socio-economic group with minimal formal education.

Caesarean section rates increased with increasing parity in our study ( $p<0.001)$. A Nigerian study found increased caesarean section rates for grand multiparous women ${ }^{34}$. Women who booked for antenatal care were less likely to have a caesarean section in this study $(\mathrm{p}=0.0018)$. This is most likely due to the fact that obstetric risk assessment would have been done in women who booked and adverse pregnancy risks appropriately managed to reduce maternal morbidity. However, a study from Lagos, Nigeria did not find any association between booking for antenatal care and caesarean section ${ }^{35}$.

In our study, previous caesarean section (20.6\%) and cephalopelvic disproportion (CPD) (20.2\%) were the commonest indications for caesarean section. Women who had had a previous caesarean section were 2.75 times more likely to have a repeat caesarean section in this study $(p<0.0001)$. This is in keeping with previous studies ${ }^{26,36}$. Most of the caesarean deliveries done in the study were emergency procedures (87\%). This is in keeping with several West African Studies that have shown that emergency caesarean deliveries were performed more commonly than elective procedures ${ }^{13,35,37}$. The outcome for elective caesarean section is usually better than emergency surgery. Therefore, more effort is needed to decrease the rate of emergency procedures through antenatal obstetric risk assessment.

Regarding complications of caesarean section post surgery, blood transfusion was the commonest post-operative complication $(45.2 \%)$ followed by wound infection $(4.3 \%)$ and emergency hysterectomy $(2.3 \%)$. In a similar tertiary hospital based study conducted elsewhere, anaemia was the commonest post-operative complication, occurring in $32.5 \%$ women, followed by pyrexia $24 \%$ and wound infection rate of $9 \%$, blood transfusion rate was not reported ${ }^{23}$. In our study, we reported blood transfusion as proxy for anaemia, which was the commonest postoperative complication. Although the rate of blood transfusion did not correlate with the amount of blood loss at surgery (mean volume loss of $410 \mathrm{ml}$ ) that may not preclude anaemia and postpartum haemorrhage irrespective of the amount of blood loss ${ }^{38}$. It is also recognized that surgeons often under estimate blood loss during sur- 
gery $^{39-41}$. Therefore, given the need for blood transfusion in more than $45 \%$ of patients who had caesarean section in this study, we suggest that the blood loss may have been under estimated in most cases. However, unnecessary blood transfusion is also a possibility. The absence of pre-operative and post-operative haemoglobin concentration made it difficult to conclude either way and it is a limitation of the study.

Wound infection following caesarean section is a well-established complication in many studies and in different settings over the years. However, in our study we observed a $4.3 \%$ rate of wound infection which is less than $6-10 \%$ estimated in most reviews ${ }^{42}$. All caesarean sections at the study site had prophylactic antibiotics either before the abdominal incision or post-surgery for 5 days. However, the infection rate as estimated in the data collected was $4.3 \%$, which may not preclude under-reporting as anecdotal evidence suggests a higher rate of post caesarean, wound infection. Nevertheless, post-caesarean section wound infection is a significant morbidity and deserves a call for the routine use of peri-operative antibiotics in patients and this has been found to be useful in other centres $^{43}$.

A limitation of the study is the absence of anthropometric measures like height and weight that have been found to be predictors of caesarean section in other studies ${ }^{35,36}$. There was also a significant amount of missing information $(5 \%-30 \%)$ in the records.

\section{Conclusion}

The rate of caesarean section in our setting of $24 \%$ is comparable to other studies in the sub-region. The commonest indications were previous caesarean section and cephalopelvic disproportion. About 90\% of caesarean sections were done as an emergency. Low educational status, being single, increasing parity and failure to book for antenatal care all increased the risk of having a caesarean delivery in The Gambia.

\section{Acknowledgment}

The authors are grateful to Dr. Pa Amadou Sohna, Khaddijatou Kujabi and Amie Jobarteh for their help with data entry.

\section{Conflict of interest}

All the authors declare that they have no competing interests.

\section{References}

1. Sewell JE. Cesarean section - a brief history. An exhibit at the National Library of Medicine, 30 April - August 1993. Bethesda, Maryland: The United States National Library of Medicine; 1993 [cited 26 September 2017]. Available from: https://www.nlm.nih.gov/exhibition/ cesarean/.

2. World Health Organization. Appropriate technology for birth. The Lancet. 1985;326(8452):436-7.

3. World Health Organization. WHO Statement on caesarean section rates 2015 [cited 26 September 2017].

4. Gibbons L, Belizán JM, Lauer JA, Betrán AP, Merialdi M, Althabe F. The global numbers and costs of additionally needed and unnecessary caesarean sections performed per year: overuse as a barrier to universal coverage. World Health report 2010. World Health Organization; 20102010.

5. Krychowska A, Kosinska K, Karwan-Plonska A. Comparison of indications for cesarean section in 198586 and 2000-01. Analysis of changes. Ginekologia polska. 2004;75(12):926-31.

6. Penn Z, Ghaem-Maghami S. Indications for caesarean section. Best Practice \& Research Clinical Obstetrics \& Gynaecology. 2001;15(1):1-15. PubMed

7. Shearer EL. Cesarean section: medical benefits and costs. Soc Sci Med. 1993;37(10):1223-31.

8. Barber EL, Lundsberg L, Belanger K, Pettker CM, Funai EF, Illuzzi JL. Contributing Indications to the Rising Cesarean Delivery Rate. Obstetrics and gynecology. 2011;118(1):29-38.

9. Niino Y. The increasing cesarean rate globally and what we can do about it. Bioscience trends. 2011;5(4):13950. PubMed

10. Souza JP, Gulmezoglu A, Lumbiganon P, Laopaiboon M, Carroli G, Fawole B, et al. Caesarean section without medical indications is associated with an increased risk of adverse short-term maternal outcomes: the 2004-2008 WHO Global Survey on Maternal and Perinatal Health. BMC Medicine. 2010;8:71.

11.Danforth DN. Cesarean section. JAMA. 1985;253(6):811-8. PubMed

12. Pallasmaa N, Ekblad U, Aitokallio-Tallberg A, Uotila J, Raudaskoski T, Ulander VM, et al. Cesarean delivery in Finland: maternal complications and obstetric risk factors. Acta obstetricia et gynecologica Scandinavica. 2010;89(7):896902.

13. Bukar M, Audu BM, Massa AA. Caesarean delivery at the Federal Medical Centre Gombe: a 3-year experience. 
Nigerian journal of medicine: Journal of the National Association of Resident Doctors of Nigeria. 2009;18(2):179-83.

14. Ali Y. Analysis of caesarean delivery in Jimma Hospital, South-Western Ethiopia. East Afr Med J. 1995;72(1):603. PubMed

15. Jackson N, Paterson-Brown S. Physical sequelae of caesarean section. Best Practice \& Research Clinical Obstetrics \&. Gynaecology. 2001;15(1):49-61. PubMed

16. Smith GC, Pell JP, Dobbie R. Caesarean section and risk of unexplained stillbirth in subsequent pregnancy. Lancet. 2003;362(9398):1779-84. PubMed

17. Hoestermann CF, Ogbaselassie G, Wacker J, Bastert G. Maternal mortality in the main referral hospital in The Gambia, West Africa. Trop Med Int Health. 1996;1.

18. O’Neill SM, Kearney PM, Kenny LC, Khashan AS, Henriksen TB, Lutomski JE, et al. Caesarean Delivery and Subsequent Stillbirth or Miscarriage: Systematic Review and Meta-Analysis. PLOS ONE. 2013;8(1): e54588. PubMed

19. Lavender T, Hofmeyr GJ, Neilson JP, Kingdon C, Gyte GML. Caesarean section for non-medical reasons at term. The Cochrane database of systematic reviews. 2012; 3: CD004660-CD.

20. MacDorman MF, Menacker F, Declercq E. Cesarean birth in the United States: epidemiology, trends, and outcomes. Clinics in perinatology. 2008;35(2):293-307, v.

21. Feng XL, Xu L, Guo Y, Ronsmans C. Factors influencing rising caesarean section rates in China between 1988 and 2008. Bull World Health Organ. 2012;90(1):30-9, 9 A.

22. Mazzoni A, Althabe F, Liu NH, Bonotti AM, Gibbons L, Sanchez AJ, et al. Women's preference for caesarean section: a systematic review and meta-analysis of observational studies. Bjog. 2011;118(4):391-9. PubMed 23. Ugwu EOV, Obioha KCE, Okezie OA, Ugwu AO. A Five-year Survey of Caesarean Delivery at a Nigerian Tertiary Hospital. Annals of Medical and Health Sciences Research. 2011;1(1):77-83.

24. Stanton CK, Holtz SA. Levels and trends in cesarean birth in the developing world. Stud Fam Plann. 2006;37(1):41-8. PubMed

25. Vogel JP, Betran AP, Vindevoghel N, Souza JP, Torloni MR, Zhang J, et al. Use of the Robson classification to assess caesarean section trends in 21 countries: a secondary analysis of two WHO multicountry surveys. The Lancet Global health. 2015;3(5):e260-70.
26. Al Busaidi I, Al-Farsi Y, Ganguly S, Gowri V. Obstetric and Non-Obstetric Risk Factors for Cesarean Section in Oman. Oman Medical Journal. 2012;27(6):478-81.

27. Peipert JF, Bracken MB. Maternal age: an independent risk factor for cesarean delivery. Obstet Gynecol. 1993;81(2):200-5. PubMed

28. Bayrampour H, Heaman M. Advanced maternal age and the risk of cesarean birth: a systematic review. Birth. 2010;37.

29. Rahman M, Ahmad Shariff A, Shafie A, Saaid R, Md Tahir R. Determinants of Caesarean Risk Factor in Northern Region of Bangladesh: A Multivariate Analysis. Iranian Journal of Public Health. 2014;43(1):16-27.

30. Rajabi A, Maharlouei N, Rezaianzadeh A, Rajaeefard

A, Gholami A. Risk factors for C-section delivery and population attributable risk for $\mathrm{C}$-section risk factors in Southwest of Iran: a prospective cohort study. Medical Journal of the Islamic Republic of Iran. 2015;29:294-.

31. Faisal-Cury A, Menezes PR, Quayle J, Santiago K, Matijasevich A. The relationship between indicators of socioeconomic status and cesarean section in public hospitals. Revista de Saúde Pública. 2017;51:14.

32. Cesaroni G, Forastiere F, Perucci CA. Are cesarean deliveries more likely for poorly educated parents? A brief report from Italy. Birth. 2008;35(3):241-4. PubMed 33. Räisänen S, Gissler M, Kramer MR, Heinonen S. Influence of delivery characteristics and socioeconomic status on giving birth by caesarean section - a cross sectional study during 2000-2010 in Finland. BMC Pregnancy and Childbirth. 2014;14:120-.

34. Odukogbe AA, Adewole IF, Ojengbede OA, Olayemi O, Fawole BO, Ahmed Y, et al. Grandmultiparity--trends and complications: a study in two hospital settings. Journal of obstetrics and gynaecology: The Journal of the Institute of Obstetrics and Gynaecology. 2001;21(4):361-7.

35. Akinola OI, Fabamwo AO, Tayo AO, Rabiu KA, Oshodi YA, Alokha ME. Caesarean section - an appraisal of some predictive factors in Lagos Nigeria. BMC Pregnancy and Childbirth. 2014;14(1):217.

36. Tandu-Umba B, Mbangama MA, Kamongola KMB, Kamgang Tchawou AG, Kivuidi MP, Kasonga Munene S, et al. Pre-pregnancy high-risk factors at first antenatal visit: how predictive are these of pregnancy outcomes? International Journal of Women's Health. 2014;6:1011-8. PubMed 37. Swende TZ. Emergency caesarean section in a Nigerian tertiary health centre. Nigerian Journal of Medicine: Jour- 
nal of the National Association of Resident Doctors of Nigeria. 2008;17(4):396-8.

38. Mavrides E, Allard S, Chandraharan E, Collins P, Green L, Hunt B, et al. Prevention and Management of Postpartum Haemorrhage: Green-top Guideline No. 52. Bjog. 2017;124(5):e106-e49.

39. Ram GG, Suresh P, Vijayaraghavan PV. Surgeons often underestimate the amount of blood loss in replacement surgeries. Chinese Journal of Traumatology $=$ Zhonghua chuang shang za zhi. 2014;17(4):225-8.

40. Schorn MN. Measurement of blood loss: review of the literature. J Midwifery Womens Health. 2010;55.
41. Thornton JA. Estimation of blood loss during surgery. Annals of The Royal College of Surgeons of England. 1963;33(3):164-74.

42. Smaill FM, Gyte GML. Antibiotic prophylaxis versus no prophylaxis for preventing infection after cesarean section. The Cochrane database of systematic reviews. 2010(1):CD007482-CD.

43. Ujah IAO, Olarewaju RS, Otubu JAM. Prophylactic amoxicillin-clavulanic acid in elective cesarean section. Current Therapeutic Research. 1992;52(5):647-51. 